\title{
Communicating amidst the noise: modeling the aggregate influence of ambient and vessel noise on baleen whale communication space in a national marine sanctuary
}

\author{
Danielle Cholewiak ${ }^{1, *}$, Christopher W. Clark ${ }^{2}$, Dimitri Ponirakis ${ }^{2}$, \\ Adam Frankel ${ }^{3}$, Leila T. Hatch ${ }^{4}$, Denise Risch ${ }^{5}$, Joy E. Stanistreet ${ }^{6}$, Michael Thompson ${ }^{4}$, \\ Elizabeth $\mathrm{Vu}^{7}$, Sofie M. Van Parijs ${ }^{1}$ \\ ${ }^{1}$ Northeast Fisheries Science Center, National Marine Fisheries Service, National Oceanic and Atmospheric Administration, \\ 166 Water Street, Woods Hole, MA 02543, USA \\ ${ }^{2}$ Bioacoustics Research Program, Cornell Laboratory of Ornithology, Cornell University, 159 Sapsucker Woods Road, Ithaca, \\ NY 14850, USA \\ ${ }^{3}$ Marine Acoustics, Inc., 4350 Fairfax Drive, Suite 600, Arlington, VA 22203, USA \\ ${ }^{4}$ Stellwagen Bank National Marine Sanctuary, National Oceanic and Atmospheric Administration, 175 Edward Foster Road, \\ Scituate, MA 02066, USA \\ ${ }^{5}$ Scottish Association for Marine Science, Oban, Argyll PA37 1QA, UK \\ ${ }^{6}$ Fisheries and Oceans Canada, Bedford Institute of Oceanography, 1 Challenger Drive, Dartmouth, NS B2Y 4A2, Canada \\ ${ }^{7}$ Scripps Institution of Oceanography, Marine Physical Laboratory, University of California, San Diego, 9500 Gilman Drive,
} La Jolla, CA 92093, USA

\begin{abstract}
Anthropogenic noise negatively impacts many species. One of the more insidious effects of elevated noise levels is the reduction in area over which animals are able to acoustically communicate, often termed communication masking. This study utilizes modeling approaches to evaluate relative levels of masking for 4 baleen whale species from the combination of current ambient noise conditions and noise from discrete vessels operating in the Stellwagen Bank National Marine Sanctuary. Acoustic data were collected using bottom-mounted autonomous recorders. One day was analyzed for each of 5 different species-specific sound types, corresponding to peaks in occurrence of fin and humpback whale songs, humpback whale social sounds, minke whale pulse trains and North Atlantic right whale gunshots. Source levels for animals and 3 categories of vessels were calculated empirically; sound propagation was modeled using Bellhop ray tracing. An agent-based modeling framework was used to calculate changes in communication space (CS) in comparison to reference conditions (10 dB lower than current ambient noise). In these singleday snapshots, current ambient noise and noise from vessels for which automatic identification system (AIS) data were available contribute most heavily to loss of CS, followed by whale-watching and fishing vessels. Right whale gunshots experience the least amount of masking, while fin, humpback and minke whale signals experience masking levels of $80 \%$ or more. While these results incorporate several simplifying assumptions, this study further develops the framework by which to comparatively quantify masking, providing information on the relative degree of masking experienced between species and allowing for important insights on the relative contributions of different anthropogenic sound sources.
\end{abstract}

KEY WORDS: Communication space $\cdot$ Baleen whales $\cdot$ Communication masking $\cdot$ Anthropogenic noise

${ }^{*}$ Corresponding author: danielle.cholewiak@noaa.gov
(C) The authors and, outside the USA, the US government 2018. Open Access under Creative Commons by Attribution Licence. Use, distribution and reproduction are unrestricted. Authors and original publication must be credited.

Publisher: Inter-Research · www.int-res.com 


\section{INTRODUCTION}

A fundamental function of animal communication is the transmission of information between senders and receivers (Bradbury \& Vehrencamp 2011). These messages may contain information relevant for foraging, navigation, reproduction and other social behaviors. These signals, as well as non-intentional sounds, may also be detected and exploited by unintended receivers through eavesdropping, such as by other species for the purposes of predator evasion or prey discovery (e.g. Evans \& Evans 2007, Ratcliffe \& Nydam 2008, King \& Janik 2015). The detection of intentional acoustic communication signals and other acoustic cues is vital to critical life functions for many species.

The area over which an individual's sounds can be detected by its intended receivers can be thought of as its communication space (CS), also called active space in the literature on terrestrial species (Brenowitz 1982, Klump 1996). A reduction of CS due to noise in the environment is referred to as acoustic masking (Lohr et al. 2003, Clark et al. 2009) and may cause a loss of information between senders and receivers, as well as others eavesdropping on the message. Acoustic masking may have a wide range of potential repercussions across marine animal taxa (e.g. Ellison et al. 2012, Popper \& Hawkins 2012, Richardson et al. 2013), by influencing their behavior (Williams et al. 2014a), their capacity to effectively communicate (Blackwell et al. 2013) or their ability to hear information pertinent to their long-term survival and health, such as for orientation (Holles et al. 2013) or foraging (Wale et al. 2013, Voellmy et al. 2014). Acoustic masking is particularly problematic for species such as marine mammals that rely heavily on sound as their primary sensory modality.

In the ocean, masking of acoustic signals can be caused by a wide range of factors, including biotic (e.g. fish choruses), abiotic (e.g. ice, rain, wind) and anthropogenic activities (e.g. construction, oil and gas prospecting, vessel traffic) (Bass \& Clark 2003, Clark et al. 2009, Ellison et al. 2012, Moore et al. 2012). Shipping is a primary contributor to noise in the low-frequency (e.g. <1000 Hz) marine acoustic environment. Since the early 1960s, there has been a dramatic increase in ship traffic, both commercial and recreational (Eyring et al. 2005, McDonald et al. 2006). Vessel noise levels and spectral signatures vary based on ship characteristics and operations (McKenna et al. 2012, 2013). To date, a number of studies have focused specifically on the effects of vessel noise in reference to both its direct and indirect impacts on marine animals (e.g. Parks et al. 2007,
Holt et al. 2009, Slabbekoorn et al. 2010, Rolland et al. 2012, Bruintjes \& Radford 2013, Wale et al. 2013, Williams et al. 2014b). However, most of these studies either isolate a single source from a single vessel type or combine vessel noise together as one general category. While previous efforts have developed methods to model aggregate vessel noise (Erbe et al. 2012, Ellison et al. 2016), to our knowledge, no studies to date have separated the influences of the aggregate noise from multiple vessel types on an animal's acoustic CS.

Clark et al. (2009) present an analytical paradigm for quantifying changes in an animal's acoustic CS as a result of spatial, spectral and temporal changes in background noise. A change in CS relative to historically quiet noise conditions yields a metric for communication masking. These CS and communication masking metrics have been used to evaluate masking in several species. Within this framework, the choice of an appropriate reference noise level is crucial for understanding changes in CS. Hatch et al. (2012) used this approach to show that a subset of the North Atlantic right whale Eubalaena glacialis population could lose 63 to $67 \%$ of its CS when foraging in essential habitat, when compared to a reference noise level of $10 \mathrm{~dB}$ less than current ambient noise conditions, a conservative estimate of pre-industrial ocean noise levels. Williams et al. (2014b) expanded on this work and evaluated loss of CS for killer whales Orcinus orca, fin whales Balaenoptera physalus and humpback whales Megaptera novaeangliae across 12 sites varying in background noise intensity within the Canadian Pacific Ocean. Williams et al. (2015) also extended the concept of noise influences on the marine acoustic environment to argue the rationale for protecting quiet regions.

There are several important aspects of these CS and masking metrics that have not yet been well explored. In this study, we focus on 2 of these. The first is consideration of the relative degree of masking that occurs between species, as well as for a single species producing sounds in different behavioral contexts, all within the same habitat. Four baleen whale species regularly occupy the waters of Massachusetts Bay and the Stellwagen Bank National Marine Sanctuary (SBNMS) at different times of year: fin, humpback, minke B. acutorostrata and North Atlantic right whales. Each species produces a variety of low-frequency sounds, which vary depending on the function of the signal or behavioral state of the animals. For example, right whale up-calls function as contact calls (e.g. Clark \& Clark 1980, Clark 1983, Parks \& Clark 2007), while there is some evidence that their gunshot sounds may function in part as a 
male display behavior (e.g. Parks et al. 2012, Matthews et al. 2014). Male humpback whales produce song sequences as a reproductive display (e.g. Payne \& McVay 1971), but both sexes produce a variety of transient social sounds in contexts associated with breeding, feeding and migration (e.g. Chabot 1988, Dunlop et al. 2007, Stimpert 2010). Male fin whale songs consist of simple patterned sequences of notes (Clark et al. 2002, Croll et al. 2002), and minke whales produce patterned sequences of units (called pulse trains) which are also suspected to function as songs (Mellinger et al. 2000, Risch et al. 2014). These sounds all vary in their acoustic characteristics, including frequency band and amplitude, which will affect the extent to which each is masked in a noisy environment.

Our second focus considers mechanisms by which to quantify and better understand the relative contributions of different vessel types to the anthropogenic noise component of an acoustic environment. For the purposes of this study, we divide vessels into 3 main types: large commercial ships carrying automatic identification system (AIS) transmitters (AIS vessels), smaller local fishing vessels and local whale-watching vessels. Vessels in these 3 categories constitute the majority of the vessel activity in the region, and vessels within each of these categories have largely similar operational patterns. For example, large commercial ships have well-defined, year-round traffic patterns as they transit in and out of designated ports, primarily within the traffic separation scheme (TSS). Fishing vessels move throughout the region in response to the distribution of their target catch species, often moving very slowly when actively engaged in fishing. Finally, whale-watching vessels primarily operate seasonally in areas specifically where whales are typically aggregated, and multiple boats may be present around a group of animals at any one time. The number of vessels within each type varies spatially and seasonally, so quantifying how each type contributes to masking is important for understanding the aggregate effect that these simultaneous anthropogenic activities can have on the acoustic environment within a particular area.

The relative contribution of different vessel types to the local noise field, as well as the mitigation strategies that may be appropriate to address noise concerns, will vary depending on the vessel category and type of activity. There is international concern over the potential effects of increasing noise in the marine environment, and ongoing international effort to develop noise management strategies (e.g. the European Union's Marine Strategy Framework
Directive 2008/56/EC). The United States developed an Ocean Noise Strategy framework, which includes guidelines for the management of acoustic habitats and soundscape characterization (cetsound.noaa.gov/ ons) (Hatch et al. 2016). Developing the methodology by which to better understand the influence of noise on animal CS, and evaluate both the separate and aggregate contributions from different vessel types, will provide important information and tools to inform conservation and management goals for threatened and endangered species.

The main objectives of this study are to implement modeling techniques to quantify the relative levels of masking experienced by 4 baleen whale species as a result of current ambient noise conditions and aggregate discrete noise from 3 vessel categories. The species and sound types include fin whale song, humpback whale social sounds, humpback whale song, minke whale pulse trains and right whale gunshot sounds. Because the potential masking of right whale up-calls was extensively analyzed in a previous study (Hatch et al. 2012), no new analysis was conducted on this call type, but results from that study are discussed in relation to right whale gunshots. For each of these species-specific sounds, the CS and the loss thereof are calculated using a custom-built model operating in a manner similar to Clark et al. (2009), in relation to the ambient noise and vessel types that were present during five $24 \mathrm{~h}$ time periods.

\section{METHODS}

\section{Acoustic data collection}

Multi-year passive acoustic data were collected as part of a long-term project in the SBNMS and surrounding waters from December 2007 to May 2010 (Fig. 1, Hatch et al. 2008, 2012). Arrays of up to 10 marine autonomous recording units (MARUs, Calupca et al. 2000) were deployed for up to 3 mo at a time and were moored 1 to $2 \mathrm{~m}$ above the sea floor in water depths ranging from 30 to $100 \mathrm{~m}$. Units were recovered and redeployed throughout the study period. MARUs were programmed to record continuously at a sampling rate of $2000 \mathrm{~Hz}$ (HTI 94-SSQ hydrophone, sensitivity with preamplifier of $-168 \mathrm{~dB}$

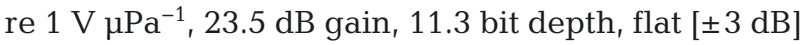
frequency response from 10 to $585 \mathrm{~Hz}$ ). Once recovered, data from all MARUs within each deployment were extracted, synchronized to $\pm 1 \mathrm{~ms}$ and merged to create multi-channel files. A subset of these data was used in the current study. 
Fig. 1. Study area showing the boundary of the Stellwagen Bank National Marine Sanctuary (SBNMS) and surrounding waters, with an example receiver grid overlay corresponding to the modeling area for an analysis. The actual modeling area varied between analyses, based on the distribution and estimated communication ranges for different species. The marine autonomous recording unit (MARU) sites (black pentagons) shown here correspond to the spatial distribution of sensors. The Northeastern Regional Association of Coastal Ocean Observing Systems [NERACOOS] oceanographic buoy (white dot) was used to extract wind data for each of the study days. Main ports in the region and the traffic separation scheme (TSS) for Boston are also identified on the map

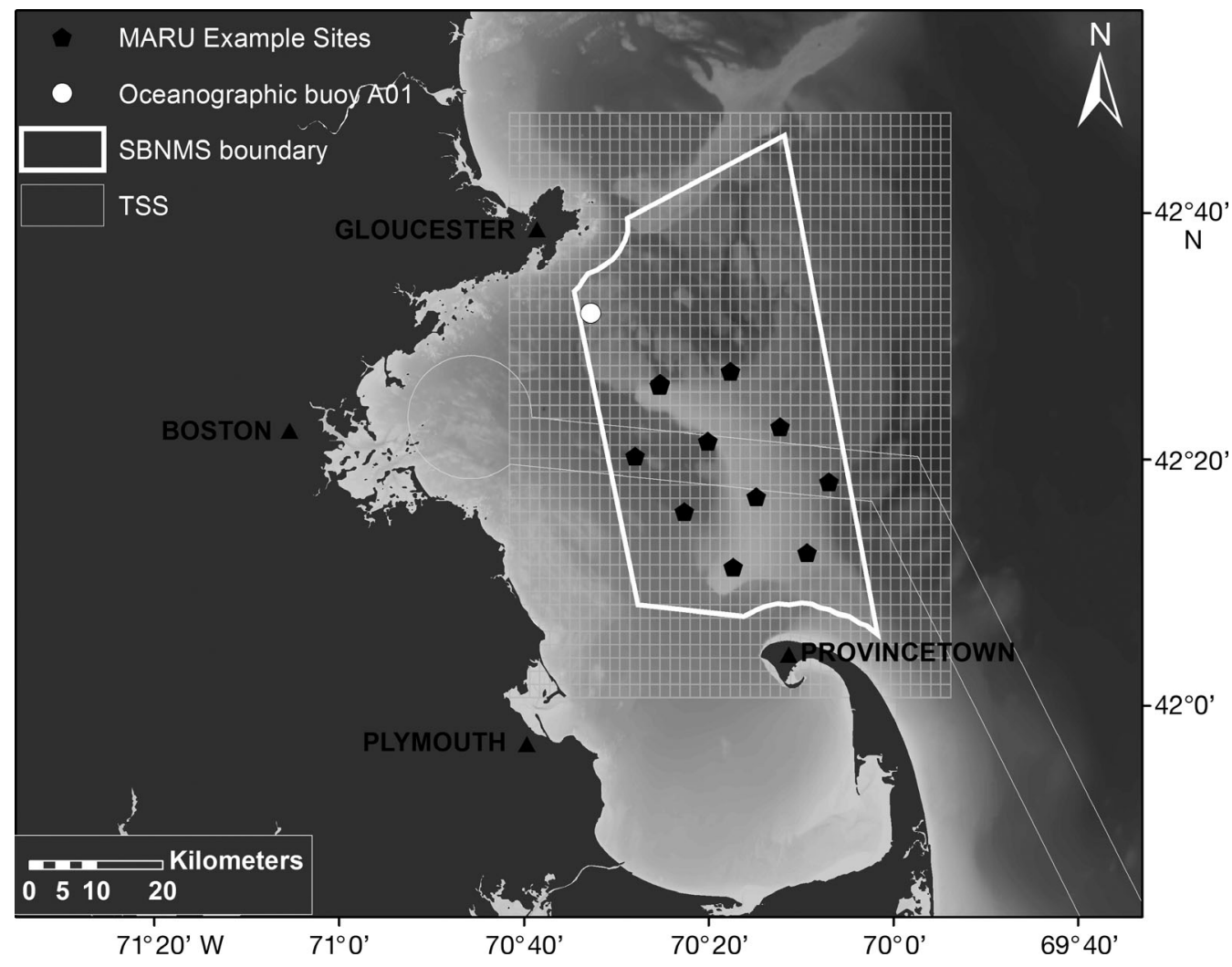

\section{Model construction: data inputs}

Communication masking is defined as the decrease in the area over which an animal can communicate in the presence of interfering sounds (Clark et al. 2009). In this study, we examined the effects of current background ambient noise levels (weather plus distant vessel noise) and discrete vessel noise on CS. Masking was quantified by calculating the change in CS under these different noise conditions, as compared to that available under reference noise conditions.

To conduct this analysis, an agent-based model was constructed that allowed for the calculation of CS (and loss thereof under different noise conditions) on a per-individual basis, in 10 min time steps over a $24 \mathrm{~h}$ analysis day. Modeling was conducted using SEDNA (Dugan et al. 2011), a custom-built software package modified to incorporate the Acoustics Toolbox (Porter 2007) including the Bellhop propagation model. The model was comprised of multiple data inputs including simulated baleen whales (animats), an ambient noise layer, vessel noise layers and an underlying grid of potential receivers, following the framework described by Clark et al. (2009). All noise levels were quantified in one-third octave bins and then across the frequency range relevant for each species' specific sound type. The $90 \times 90 \mathrm{~km}$ study area encompassing the SBNMS and surrounding waters was divided into either $1 \times 1 \mathrm{~km}$ or $2 \times 2 \mathrm{~km}$ grid cells, depending on the species/sound type (see Fig. 1 for the study area and an example grid from one of the analyses). Each of the data inputs was informed with empirical data as described in the rest of the methods below. The potential communication range, area and resultant masking index were calculated in the target frequency band for each animat at each 10 min interval.

Baleen whale data

Based on our understanding of the timing and presence of fin, humpback, minke and North Atlantic right whales in the SBNMS (Morano et al. 2012, Mussoline et al. 2012, Vu et al. 2012, Risch et al. 2013), 1 representative day was selected for each of the 5 baleen whale sound types evaluated in this study. Each day occurred within the high period of seasonal occurrence of fin whale song, humpback whale song, humpback whale social sounds, minke whale pulse trains and North Atlantic right whale gunshots. 
Table 1. Summary of baleen whale input data. Analysis date was chosen based on seasonal occurrence of species within the study area. Numbers of animats per day were chosen based on general patterns in animal density as documented from aerial survey data. Frequency band refers to the lower and upper limits of the one-third octave bands used in communication space modeling analyses. Average source levels (SLs) for each sound type were calculated based on empirical data

\begin{tabular}{|c|c|c|c|c|c|c|c|}
\hline Species & $\begin{array}{l}\text { Sample date } \\
\text { (mo/d/yr) }\end{array}$ & $\begin{array}{l}\text { No. of whale } \\
\text { animats } d^{-1}\end{array}$ & $\begin{array}{l}\text { Sound } \\
\text { type }\end{array}$ & $\begin{array}{l}\text { Frequency } \\
\text { band (Hz) }\end{array}$ & $\begin{array}{l}\text { No. of sounds } \\
\text { for SL analysis }\end{array}$ & $\begin{array}{l}\text { Mean SL } \\
\text { (dB) }\end{array}$ & $\mathrm{SD}$ \\
\hline Fin whale & 12/23/09 & 4 & Song & $18-22$ & 215 & 180 & 5.4 \\
\hline Humpback whale & $4 / 12 / 09$ & 6 & Song & $36-355$ & 281 & 170 & 2.9 \\
\hline Humpback whale & $7 / 16 / 09$ & 50 & Social & $36-355$ & 99 & 164 & 5.5 \\
\hline Minke whale & 10/3/09 & 9 & Pulse train & $56-355$ & 87 & 163 & 3.9 \\
\hline North Atlantic right whale & $1 / 24 / 08$ & 3 & Gunshot & $36-891$ & 85 & 206 & 4.5 \\
\hline
\end{tabular}

Animat numbers and distributions

For each selected day, the number of animals and their distributions within the SBNMS area were estimated based on typical aerial survey sightings, collected via long-term surveys of this region by the NOAA Northeast Fisheries Science Center (Khan et al. 2014). This information was used to program simulated acoustically active animals, or animats, that were used for all analyses of communication masking (Frankel et al. 2002). Animats were programmed to wander within the study area according to predefined movement parameters (speeds ranging from 3.7 to $9.3 \mathrm{~km} \mathrm{~h}^{-1}$, turning radii of 22.5 to $45^{\circ}$ ). Minke and fin whale animats were allowed to wander throughout the entire study area. North Atlantic right whale animats were confined to the northern area of the SBNMS, which represents the portion of their winter distribution in the SBNMS. Humpback whale animats were confined to 2 smaller subregions corresponding to areas within the SBNMS that are known to be heavily utilized by humpback whales, particularly when foraging. Animats were simulated to produce a sound (call, gunshot or song) at a depth of $5 \mathrm{~m}$ from their location every $10 \mathrm{~min}$. The number of baleen whale animats per species and analysis day ranged from 3 to 50 (Table 1).

\section{Source level calculations}

The relevant frequency band for each sound type (Table 1, Fig. 2) was chosen based on previously published reports and spectrographic analyses of the MARU data. For fin whales and minke whales, the bandwidths for $20 \mathrm{~Hz}$ song units (Watkins et al. 1987) and pulse trains (Risch et al. 2013), respectively, were based on measurements reported in the literature. Right whale gunshots are broadband signals with frequency content that can exceed the highest fre- quency sampled by our recorders (Parks \& Tyack 2005); thus, we utilized the full frequency range of the acoustic data (10 to $1000 \mathrm{~Hz}$ ). The humpback whale acoustic repertoire is diverse and changes over time; therefore, 1 frequency band representing 2 social call types and 2 song units that were predominant at the time was chosen based on spectrographic analyses.

Source levels (SLs) for each sound type were estimated empirically by a separate analysis in which actual individual vocalizing whales were localized using the time-aligned MARU data. See Supplement 1 (at www.int-res.com/articles/suppl/n036p059 _supp.pdf) for more details on the localization and SL analyses. Average SLs derived from the empirical analyses (Table 1) were assigned to each animat, and sounds were propagated across the study area using the Bellhop propagation model.

\section{Ambient noise layer}

Ambient noise levels at a single MARU closest to the site of a moored oceanographic buoy (Northeastern Regional Association of Coastal Ocean Observing Systems [NERACOOS] Gulf of Maine A01, www. neracoos.org, Fig. 1) were calculated for each $10 \mathrm{~min}$ period for each analysis day. The bottom $5^{\text {th }}$ percentile of these noise data was regressed against wind speed recorded at the buoy, and the resulting relationship was used to predict the wind speed contribution to ambient noise levels for each $10 \mathrm{~min}$ time period within a day, based on wind speed at that time. This level is defined as the present ambient (PrA) noise level. This approach was taken to remove the influence of discrete nearby vessel transits and more accurately represent background ambient noise levels, which include contributions from wind as well as distant shipping and other non-discrete sources. For the purposes of computing present 


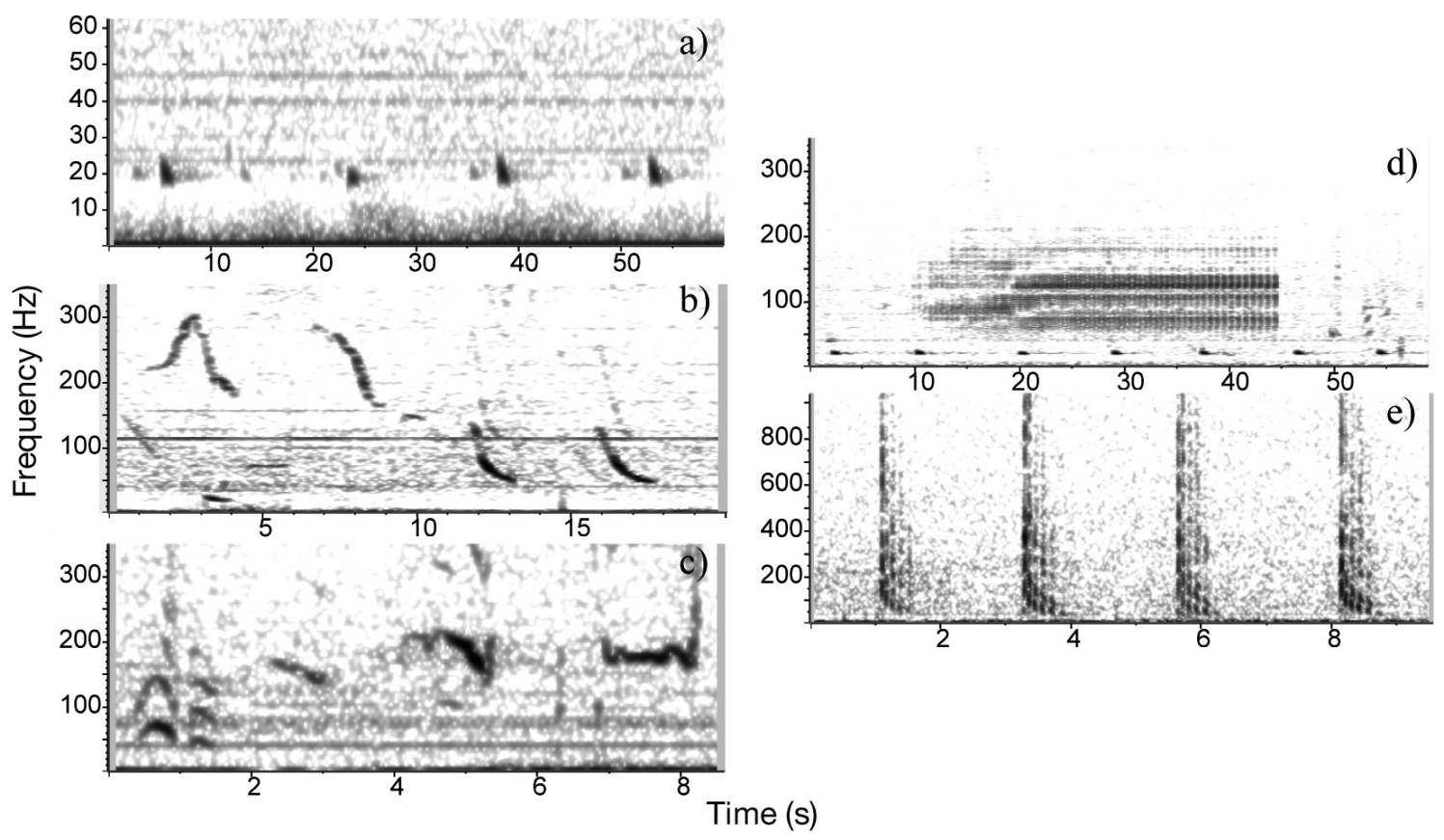

Fig. 2. Spectrograms of sound types included in analyses (fast Fourier transform: 1024 or 2048 pt, $90 \%$ overlap, Hanning window). Note that both the time and frequency axes vary between panels. (a) Fin whale $20 \mathrm{~Hz}$ song notes. Note that fin whale $20 \mathrm{~Hz}$ song notes are also present in (d). (b) Humpback song units. Two song units were used, including units with fundamental frequencies between 150 and $300 \mathrm{~Hz}$ and downsweeping units with fundamental frequencies less than $150 \mathrm{~Hz}$. (c) Humpback social sounds. Two call type categories were used, including calls with fundamental frequencies less than $100 \mathrm{~Hz}$ and calls with fundamental frequencies between 150 and $300 \mathrm{~Hz}$. (d) Minke whale 'pulse trains'. (e) North Atlantic right whale gunshots

masking indices, a reference ambient (RA) noise level is needed. In this case, RA was set at $10 \mathrm{~dB}$ less than PrA for each 10 min time period. We use this as a conservative representation of ambient levels prior to the onset of noise contributions from commercial shipping in the study area 50 to $70 \mathrm{yr}$ ago (following Hatch et al. 2012), although other studies have suggested that pre-industrial low-frequency ambient noise levels may have been up to $20 \mathrm{~dB}$ lower in some regions (Hildebrand 2009). Values for ambient noise were applied spatially across the study area, such that a single static ambient noise layer was used throughout the entire study area for each $10 \mathrm{~min}$ period.

\section{Vessel noise layers}

Three categories of vessels that regularly utilize the waters within Massachusetts Bay and the SBNMS (Fig. 1) were included in the analyses: AIS vessels, fishing vessels and whale-watching vessels. AIS vessels denote ships carrying AIS transmitters, which are required for all ships over 300 gross tons, those carrying more than 165 passengers and tug boats. For masking calculations, AIS vessels were considered as 1 group but were also divided into 3 subgroups for exploratory analyses: industrial vessels (e.g. cargo ships, tankers, tugs), research/military vessels (e.g. United States Coast Guard vessels) and passenger vessels (e.g. passenger ships, recreational boats, yachts). Fishing vessels include a variety of commercial boats using stationary gear (e.g. crab pots, lobster pots) and boats using mobile gear (e.g. trawl, dredge, hook and line). Commercial whalewatching vessels considered in this study typically comprised boats of $30 \mathrm{~m}$ or more that accommodated over 100 passengers.

\section{Vessel numbers and distributions}

Numbers and tracks of AIS vessels operating on each analysis day were directly extracted from AIS data (as in Hatch et al. 2008, Fig. 3a). The numbers of fishing vessels operating each day were obtained from the vessel monitoring system (VMS), in which the position of each fishing vessel is provided every 30 to $60 \mathrm{~min}$. Actual tracks of fishing vessels were not available; therefore, a static map of hourly fishing vessel occurrence across the SBNMS was created for each analysis day based on the distribution of vessels 

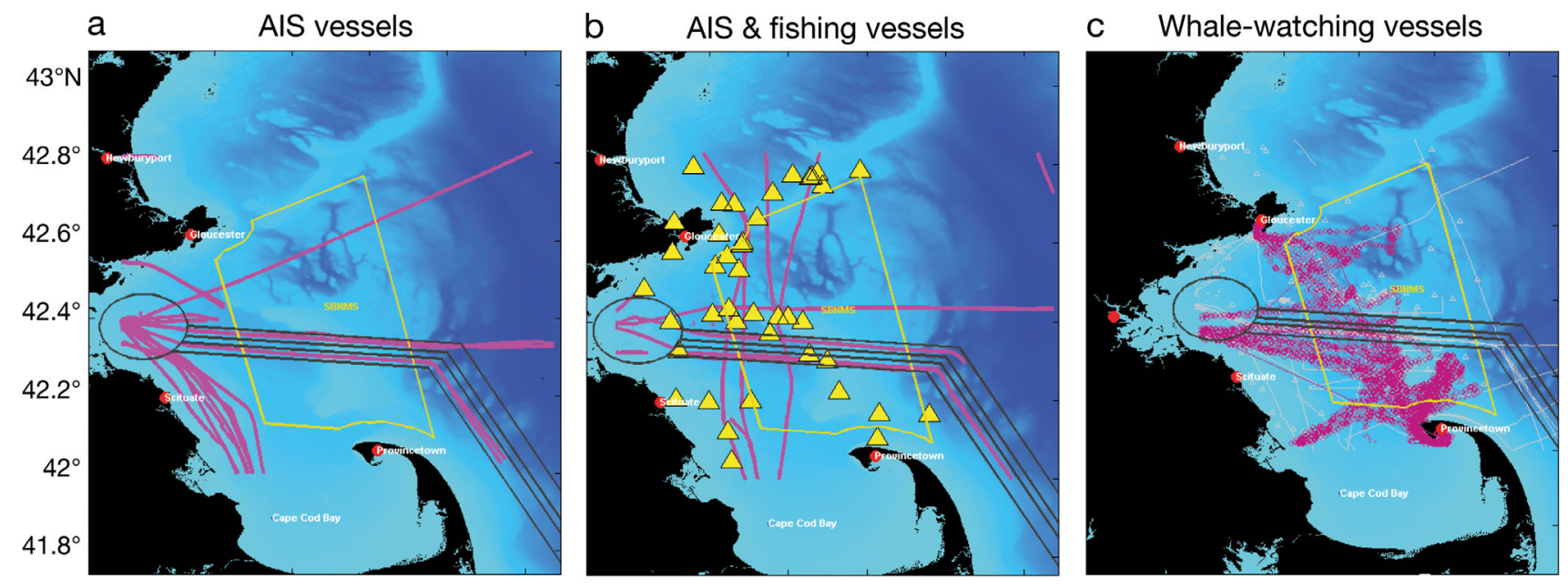

Fig. 3. Example vessel layers. (a) Tracks of automatic identification system (AIS) vessels on 24 January 2008 (pink lines). (b) Static positions of fishing vessels (yellow triangles) and tracks of AIS vessels on 12 April 2009. (c) Modeled tracks of whalewatching vessels originating out of the ports of Provincetown, Plymouth, Boston and Gloucester on 16 July 2009. In each panel, the yellow outline of the Stellwagen Bank National Marine Sanctuary (SBNMS) is shown, as is the traffic separation scheme into the port of Boston

reported in the VMS data (Fig. 3b). Individual tracks of whale-watching boats for the specific analysis dates were not available but were modeled based on data collected from typical trips within the SBNMS at the relevant times of year (Fig. 3c). Although the tracks were not directly linked to animat positions, both the whale-watching vessels and the humpback whale animats experienced a high degree of spatial overlap, as these animats were distributed between 2 typical high-use feeding areas, and whale-watching vessels generally concentrate on those areas as well. However, this approach may underestimate the influence of whale-watching vessels on communication masking of humpback whales.

\section{SL calculations}

SLs were calculated empirically using the following approach for as many vessels as possible within each category and then applied to the remaining vessels. In all cases where empirical data were available, received levels (RLs) were calculated in one-third octave bands for each known vessel using the closest point of approach (CPA) of the vessel to a MARU. Transmission loss (TL) over the range between the vessel and MARU was calculated using the Bellhop propagation model (Porter \& Liu 1994) for AIS vessels and using a TL model of $17 \times \log _{10}(r)$, where $r$ is the CPA range of the vessel to a MARU for fishing and whale-watching vessels (where CPAs were typically much closer). The methodology for applying SLs to vessels for which it was not possible to calculate empirical SLs varied by vessel type. For AIS vessels, the average SL from vessels of the same size category was used, while for fishing vessels, an SL was randomly assigned from the distribution of empirical fishing vessel measurements. Due to the paucity of available data from whale-watching vessels, the median SL from their empirical measurements was applied to all whale-watching vessels in subsequent modeling steps. See Supplement 1 for more details on the SL calculations.

The sound contribution from individual vessels was propagated across the study area using the Bellhop model. Within each vessel type, the intensity values from all vessels present in each 10 min time bin were summed and then converted to noise levels to create an aggregate vessel noise layer, in the appropriate frequency bands for each species/sound type. These noise layers are defined as the present shipping (PrS) layer.

\section{Communication masking analyses: Data integration}

Masking was quantified according to 3 different scenarios, all relative to the RA level: (1) change in CS due to levels of PrA noise alone; (2) change in CS due to discrete vessel noise; and (3) change in CS due to the combined effects of PrA noise and discrete ves- 
sel noise. It is important to recognize that this model is estimating potential communication masking, based on a grid of theoretical receivers; actual measures of communication masking would depend on real receiver locations and a calibrated measurement for the RA level.

CS was calculated according to the formulae in Clark et al. (2009), where potential CS is defined as the area within which receivers experience a signal excess (SE) of greater than zero. The calculation of SE for any potential receiver depends on the signalto-noise ratio (SNR), detection threshold (DT), directivity index (DI) and a signal processing gain (SG). In Clark et al. (2009), the DT, DI and SG values were set to 10,0 and $16 \mathrm{~dB}$, respectively. Together, these latter values contribute to what is called the recognition differential (RD), which accounts for an animal's ability not just to detect but to recognize a signal in noise. The importance of RD in the calculation of SE needs to be emphasized; when the summation of DI and SG is greater than DT, RD is negative, which leads to a situation in which the signal of interest can be recognized even when SNR < 0. Additionally, as described in Clark et al. (2009), as SE decreases and approaches zero, the probability of a receiver recognizing the signal decreases. Therefore, the area over which SE > 0 is weighted by a probability-of-recognition $(\mathrm{PR})$ term, where $\mathrm{PR}=0.5$ at $\mathrm{SE}=0 \mathrm{~dB}$ and $\mathrm{PR}=1$ at $\mathrm{SE}=18 \mathrm{~dB}$. Supplement 2 (at www.int-res.com/ articles/suppl/n036p059_supp.pdf) steps through an example analysis in more detail.

Using these values, both the maximum potential CS and the current available CS were calculated. The theoretical maximum communication range for each species under RA noise conditions is defined as the range at which their signal RL drops below the RA noise level, based on propagation estimated using the Bellhop model. The proportion of the area that is available to a sender under current noise conditions, compared to the maximum potential area that would have been available under reference noise conditions, is defined as the communication masking index and is expressed either as a value between 0 and 1 or as a percentage of CS lost under present noise conditions. The time-varying communication range, area and communication masking index were calculated per animat per 10 min period, across the receiver grid that was bounded by the theoretical maximum communication range for each animat as it moved throughout the habitat. Mean and median values from all animats within a particular model are presented for each species/sound type.

\section{RESULTS}

\section{Baleen whale data}

Baleen whale SLs were calculated for each of the 5 sound types. The number of sound samples used per analysis ranged from 85 to 281 (Table 1). Localization distances between an individual animal and the nearest MARU were $3.3 \mathrm{~km}$ on average across all measured sounds but ranged from a minimum distance of approximately $400 \mathrm{~m}$ to a maximum distance of approximately $16 \mathrm{~km}$. All SLs are reported as dB rms re $1 \mu \mathrm{Pa}$ at $1 \mathrm{~m}$. Right whale gunshots had the loudest SLs at $206 \pm 5 \mathrm{~dB}(\mathrm{n}=85)$, followed by fin whale song (180 $\pm 5 \mathrm{~dB}, \mathrm{n}=215)$, humpback whale song (170 \pm $3 \mathrm{~dB}, \mathrm{n}=281)$ and social sounds $(164 \pm 6 \mathrm{~dB}, \mathrm{n}=99)$ and, finally, minke pulse trains $(163 \pm 4 \mathrm{~dB}, \mathrm{n}=87)$.

\section{Ambient noise data layer}

The mean lower $5^{\text {th }}$ percentile of noise levels at a MARU for each analysis day ranged from 90.3 to $100.4 \mathrm{~dB}$ rms re $1 \mu \mathrm{Pa}$, depending on the date and corresponding frequency band. Mean wind speeds, as measured on the NERACOOS Gulf of Maine A01 buoy, ranged from $4.7 \pm 1.4$ to $10.3 \pm 1.7 \mathrm{~m} \mathrm{~s}^{-1}$ across analysis days. The subsequent correlation between the lower $5^{\text {th }}$ percentile of noise and wind speed ranged from $R^{2}=0.12$ to $R^{2}=0.47$.

\section{Vessel noise data layer}

The total number of vessels present per day ranged from 17 to 781 (Table 2). AIS vessel SLs were calculated for 68 of the 101 vessel transits that occurred during the 5 analysis days. Vessel speeds ranged from 5 to $50 \mathrm{~km} \mathrm{~h}^{-1}$, with a median vessel speed at CPA of $19 \mathrm{~km} \mathrm{~h}^{-1}$. For the remaining 33 vessel transits, SLs were applied from measurements of those same vessel types on different days or from other vessels of similar size category. Median one-third octave-band SLs were between 151 and $177 \mathrm{~dB}$ rms (re $1 \mu \mathrm{Pa}$ at $1 \mathrm{~m}$ ), but maximum SLs exceeded $200 \mathrm{~dB}$ for some bands (Table 3). Median SLs for the analysis bands of interest ranged from 177 to $185 \mathrm{~dB} \mathrm{rms}$ (Table 4).

AIS vessels were subdivided into 3 categories for exploratory analyses. Within the AIS category, 66 vessel transits were grouped under industry (i.e. tankers, tugs, fishing vessels), 4 vessel transits were military/research, and 31 transits were passenger 
Table 2. Summary of vessel data layers. The numbers of automatic identification system (AIS) vessels and fishing vessels per day were based on empirical data. Whale-watching vessels are only active in the summer through fall so were only relevant on 2 of the analysis days. The numbers of whale-watching vessels per day were based on the typical numbers of scheduled daily trips during that part of the season. F/V: fishing vessel; WW: whale-watching vessel

\begin{tabular}{|lcccrc|}
\hline Species/sound type & Vessel layer & $\begin{array}{c}\text { No. of AIS } \\
\text { vessels d }\end{array}$ & $\begin{array}{c}\text { No. of fishing } \\
\text { vessels d }^{-1}\end{array}$ & $\begin{array}{c}\text { No. of whale- } \\
\text { watching vessels d }^{-1}\end{array}$ \\
\hline Fin whale song & AIS, F/V & 24 & 301 & 0 & 325 \\
Humpback whale song & AIS, F/V & 16 & 176 & 0 & 192 \\
Humpback whale social sounds & AIS, F/V, WW & 23 & 729 & 5 & 781 \\
Minke whale pulse trains & AIS, F/V, WW & 21 & 353 & 0 \\
Right whale gunshots & AIS & 17 & 0 & 17 \\
\hline
\end{tabular}

(i.e. passenger boats, yachts, pleasure craft). Median SLs for industry boats were 180 to $189 \mathrm{~dB}$ rms (re $1 \mu \mathrm{Pa}$ at $1 \mathrm{~m})$, depending on the frequency band, which was 9 to $16 \mathrm{~dB}$ higher than research or passenger vessels (Table 4).

Fishing vessel SLs were calculated for 13 events from at least 8 different boats (Table 3). Five of these cases included vessel CPAs that happened just prior to a trawling event in which the MARU was hit by fishing gear; in the remaining 8 cases, vessel positions relative to a MARU were extracted from VMS data. For VMS-based data, distances at CPA ranged from 70 to $376 \mathrm{~m}$. Vessel speeds were unknown but were assumed to be approximately $4.6 \mathrm{~km} \mathrm{~h}^{-1}$ based on typical speeds during which trawling activities take place. Median SLs ranged from 136 to $155 \mathrm{~dB}$ rms (re $1 \mu \mathrm{Pa}$ at $1 \mathrm{~m}$ ), depending on the one-third octave band (Table 3 ).

For whale-watching vessels, 14 vessel transits passed within a $1.5 \mathrm{~km}$ radius of a MARU. Of these, SLs were estimated for 7 transits of 4 different boats that had clear CPAs. Vessel speeds ranged from 20 to $37 \mathrm{~km} \mathrm{~h}^{-1}$, and distances at CPA ranged from 78 to $1200 \mathrm{~m}$. Median SLs ranged from 133 to $160 \mathrm{~dB}$ rms (re $1 \mu \mathrm{Pa}$ at $1 \mathrm{~m}$ ), depending on the one-third octave band (Table 3).
Table 3. Median, minimum and maximum calculated source levels by the one-third octave band for automatic identification system (AIS), whale-watching and fishing vessel layers. AIS vessels included measurements of 68 transits. Whale-watching vessels included 6 measurements of 4 vessels, transiting at speeds of 20 to $37 \mathrm{~km} \mathrm{~h}^{-1}$. Fishing vessels included measurements from 13 events of at least 8 different vessels. All measurements are reported in $\mathrm{dB}$ rms re $1 \mu \mathrm{Pa}$ at $1 \mathrm{~m}$. Med.: median

\begin{tabular}{|c|c|c|c|c|c|c|c|c|c|}
\hline \multirow{2}{*}{$\begin{array}{l}\text { One-third } \\
\text { octave band } \\
\text { center } \\
\text { frequency }\end{array}$} & \multicolumn{3}{|c|}{ AIS vessels } & \multicolumn{3}{|c|}{ Whale-watching vessels } & \multicolumn{3}{|c|}{ Fishing vessels } \\
\hline & Med. & Max. & Min. & Med. & Max. & Min. & Med. & Max. & Min. \\
\hline 20 & 176.8 & 205.5 & 130.6 & 133.4 & 146.0 & 128.0 & 135.6 & 143.9 & 118.2 \\
\hline 25 & 175.8 & 199.5 & 128.3 & 137.6 & 144.3 & 125.5 & 135.7 & 150.0 & 129.7 \\
\hline 31.5 & 175.3 & 205.6 & 122.8 & 142.7 & 157.0 & 131.6 & 137.0 & 146.0 & 121.4 \\
\hline 40 & 175.8 & 202.2 & 139.2 & 145.5 & 161.3 & 139.8 & 140.8 & 154.1 & 123.8 \\
\hline 50 & 177.6 & 199.3 & 134.5 & 147.4 & 164.3 & 128.4 & 147.2 & 159.8 & 133.8 \\
\hline 63 & 175.0 & 194.2 & 138.1 & 151.1 & 160.1 & 131.1 & 141.9 & 156.9 & 129.1 \\
\hline 80 & 174.4 & 194.4 & 139.9 & 151.0 & 156.9 & 134.0 & 146.9 & 158.0 & 140.8 \\
\hline 100 & 171.3 & 191.4 & 141.3 & 154.3 & 157.4 & 132.7 & 153.0 & 160.4 & 147.4 \\
\hline 125 & 167.1 & 185.5 & 139.9 & 154.1 & 162.7 & 137.0 & 153.2 & 157.0 & 144.8 \\
\hline 160 & 165.1 & 182.6 & 137.1 & 155.1 & 162.7 & 139.1 & 152.4 & 164.4 & 145.0 \\
\hline 200 & 164.3 & 182.8 & 139.9 & 160.2 & 166.6 & 137.8 & 152.6 & 168.7 & 145.6 \\
\hline 250 & 160.3 & 178.1 & 134.8 & 159.3 & 166.6 & 143.9 & 154.2 & 165.7 & 145.9 \\
\hline 315 & 159.8 & 181.6 & 125.8 & 156.8 & 166.3 & 139.3 & 155.4 & 164.4 & 146.1 \\
\hline 400 & 157.4 & 173.4 & 123.4 & 157.0 & 166.6 & 139.9 & 153.7 & 161.6 & 145.8 \\
\hline 500 & 158.0 & 175.4 & 126.5 & 154.2 & 162.9 & 136.0 & 154.7 & 159.8 & 143.5 \\
\hline 630 & 155.5 & 171.7 & 122.7 & 153.9 & 161.6 & 132.3 & 152.4 & 159.3 & 143.2 \\
\hline 800 & 151.4 & 166.1 & 110.1 & 155.0 & 161.6 & 133.3 & 150.9 & 157.4 & 144.5 \\
\hline
\end{tabular}

\section{Communication masking analyses}

The maximum theoretical communication ranges for each species, under reference noise conditions, ranged from 5 to $30 \mathrm{~km}$ for our study area (Table 5). The modeled reference communication ranges, based on the positions of the animats and the distribution of receivers and reference noise conditions, were just slightly lower. The reference communication range for humpback whales was $29.7 \pm 0.1 \mathrm{~km}$ for song and $4.8 \pm 0.5 \mathrm{~km}$ for social sounds, and was $12.8 \pm 1.3 \mathrm{~km}$ for minke whale signals. Reference communication ranges were much larger for fin whale song $(29.7 \pm 0.8 \mathrm{~km})$ and for right whales producing gunshots $(29.8 \pm 0.0 \mathrm{~km})$. 


\section{Masking from ambient noise}

When compared to RA noise conditions of $10 \mathrm{~dB}$ lower, current ambient noise conditions resulted in a reduction in communication range of up to $50 \%$. Between all species, this loss ranged from 0 to $15 \mathrm{~km}$, with a median loss of $5 \pm 2.2 \mathrm{~km}$. The modeled communication area was reduced by $5 \mathrm{~km}^{2}$ to over $1900 \mathrm{~km}^{2}$, depending on the species (Fig. 4, Table 5), which is the equivalent of a mean loss of up to $92 \%$. The resulting median communication masking index calculated from PrA conditions alone ranged from 1\% (right whale gunshots) to $96 \%$ (fin whale song, Table 6).
Masking from vessel noise

When compared to reference noise conditions, masking from all vessel layers combined ranged from $4 \%$ (right whale gunshots) to $99 \%$ (humpback whale social sounds) (Table 6). In almost all cases, AIS vessels had the largest effect on masking. For humpback whale and fin whale song, aggregated noise from commercial shipping was clearly the dominant vessel layer, contributing to 85 and $90 \%$ of masking, respectively, with significantly less masking from fishing vessels (see Table 6, Fig. 5). Within AIS vessels, the relative contributions from the 3 subcategories

Table 4. Median, minimum and maximum calculated source levels (SLs) for measured automatic identification system (AIS) vessels, broken down by category. Industry vessels included tankers, tugs, containerships and fishing vessels. Passenger vessels included recreational vessels, pleasure craft, yachts and sailboats. SLs ( $\mathrm{dB}$ rms re $1 \mu \mathrm{Pa}$ at $1 \mathrm{~m}$ ) were summed over the frequency range that was relevant for each analysis

\begin{tabular}{|c|c|c|c|c|c|c|c|c|c|c|}
\hline \multirow{2}{*}{$\begin{array}{l}\text { Frequency } \\
\text { range (Hz) }\end{array}$} & \multirow{2}{*}{$\begin{array}{c}\text { All AIS vessels } \\
\text { Median }\end{array}$} & \multicolumn{3}{|c|}{ Industry vessels } & \multicolumn{3}{|c|}{ Research/military vessels } & \multicolumn{3}{|c|}{ Passenger vessels } \\
\hline & & Median & Max. & Min. & Median & Max. & Min. & Median & Max. & Min \\
\hline $18-22$ & 177 & 180 & 206 & 144 & 167 & 177 & 157 & 165 & 197 & 131 \\
\hline $36-355$ & 185 & 189 & 203 & 170 & 176 & 182 & 164 & 179 & 192 & 154 \\
\hline $56-355$ & 182 & 188 & 197 & 167 & 171 & 176 & 163 & 177 & 189 & 154 \\
\hline $36-891$ & 185 & 189 & 203 & 170 & 176 & 182 & 164 & 180 & 192 & 155 \\
\hline
\end{tabular}

Table 5. Modeled communication range and area for each species under reference ambient noise conditions, current ambient noise conditions and current noise conditions including ambient noise and vessel noise. Results are mean values \pm SD for each $24 \mathrm{~h}$ analysis day. The theoretical communication range defines the maximum range over which the modeling computations are carried out

\begin{tabular}{|c|c|c|c|c|c|c|c|}
\hline \multirow{2}{*}{ Species/sound type } & \multirow{2}{*}{$\begin{array}{l}\text { Theoretical } \\
\text { range (km) }\end{array}$} & \multicolumn{3}{|c|}{ Modeled communication range (km) } & \multicolumn{3}{|c|}{ Modeled communication area $\left(\mathrm{km}^{2}\right)$} \\
\hline & & $\begin{array}{l}\text { Reference } \\
\text { ambient }\end{array}$ & $\begin{array}{l}\text { Current } \\
\text { ambient }\end{array}$ & $\begin{array}{l}\text { Ambient } \\
+ \text { vessels }\end{array}$ & $\begin{array}{l}\text { Reference } \\
\text { ambient }\end{array}$ & $\begin{array}{l}\text { Current } \\
\text { ambient }\end{array}$ & $\begin{array}{l}\text { Ambient } \\
\text { + vessels }\end{array}$ \\
\hline Fin whale song & 30 & $29.7 \pm 0.8$ & $14.9 \pm 11.3$ & $8.5 \pm 9.8$ & $2145 \pm 733$ & $173 \pm 322$ & $30 \pm 65$ \\
\hline Humpback whale song & 30 & $29.7 \pm 0.1$ & $23.0 \pm 6.3$ & $13.7 \pm 7.4$ & $2013 \pm 328$ & $784 \pm 375$ & $303 \pm 273$ \\
\hline Humpback whale social sounds & 5 & $4.8 \pm 0.5$ & $3.4 \pm 1.6$ & $0.8 \pm 0.6$ & $69 \pm 16$ & $37 \pm 28$ & $1 \pm 3$ \\
\hline Minke whale pulse trains & 14 & $12.8 \pm 1.3$ & $8.3 \pm 2.2$ & $7.6 \pm 2.3$ & $278 \pm 110$ & $81 \pm 54$ & $58 \pm 41$ \\
\hline Right whale gunshots & 30 & $29.8 \pm 0.0$ & $29.8 \pm 0.0$ & $29.8 \pm 0.0$ & $2771 \pm 72$ & $2767 \pm 78$ & $2755 \pm 77$ \\
\hline
\end{tabular}

Table 6. Communication masking index, or overall proportion of lost communication space for each species/sound type based on noise layer. Results are median values for each $24 \mathrm{~h}$ analysis day. Masking from each vessel layer is presented separately (fishing vessel layer, whale-watching vessel layer, automatic identification system [AIS] vessel layer) as well as for all vessel layers combined. Masking due only to present ambient noise conditions and masking resulting from the combination of all vessel layers and ambient noise conditions are also presented. N/A: not applicable

\begin{tabular}{|lcccccc|}
\hline Species/sound type & $\begin{array}{c}\text { Ambient } \\
\text { only }\end{array}$ & AIS vessels & $\begin{array}{c}\text { Fishing } \\
\text { vessels }\end{array}$ & $\begin{array}{c}\text { Whale-watching } \\
\text { vessels }\end{array}$ & $\begin{array}{c}\text { All vessels } \\
\text { Vessels + } \\
\text { ambient }\end{array}$ \\
\hline Fin whale song & 0.96 & 0.90 & 0.001 & N/A & 0.90 & 0.99 \\
Humpback whale song & 0.68 & 0.85 & 0.25 & N/A & 0.85 & 0.90 \\
Humpback whale social sounds & 0.55 & 0.75 & 0.32 & 0.33 & 0.99 \\
Minke whale pulse trains & 0.76 & 0.20 & 0.27 & 0.15 & 0.48 \\
Right whale gunshots & 0.01 & 0.04 & N/A & N/A & 0.04 & 0.09 \\
\hline
\end{tabular}



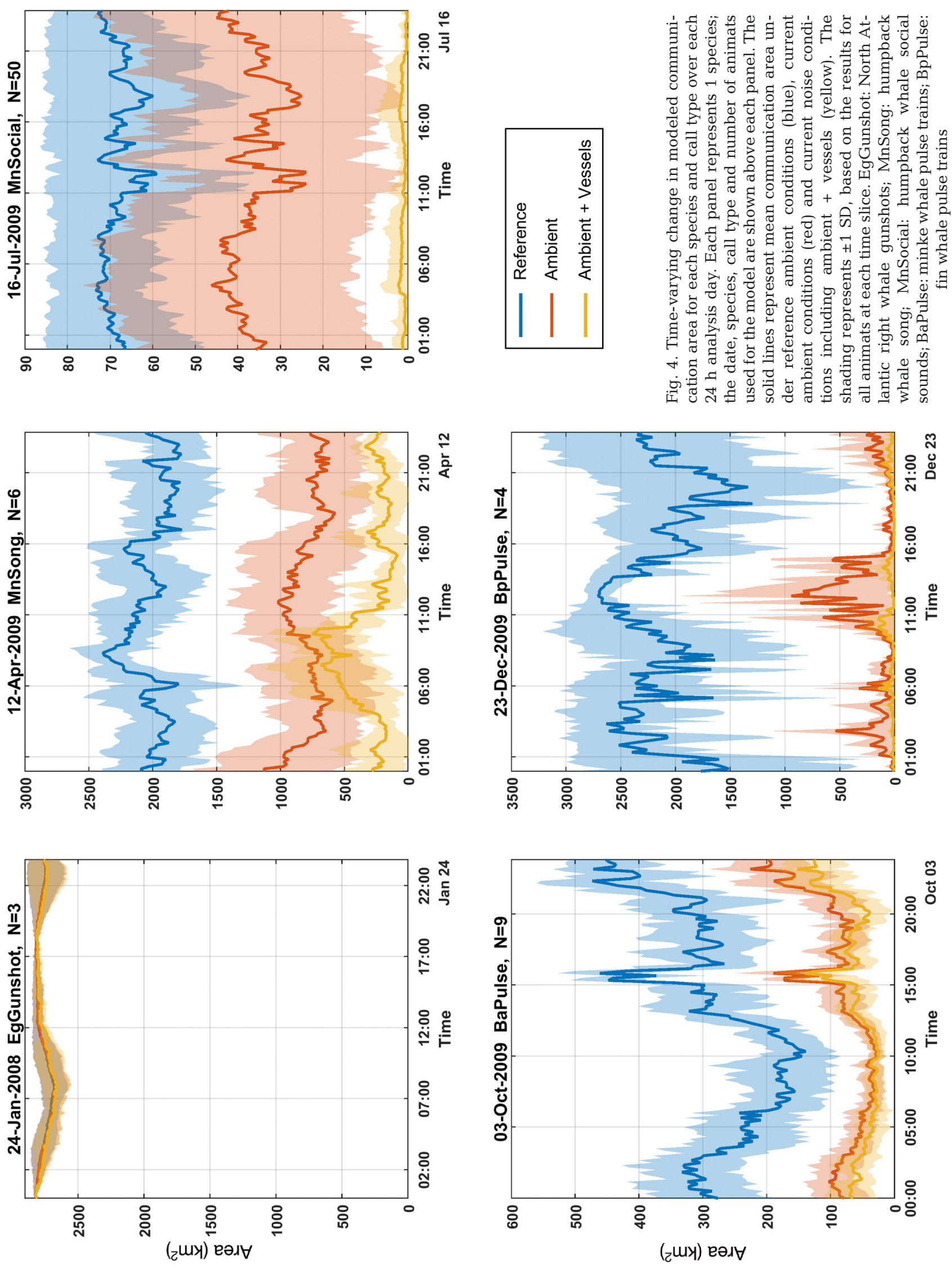


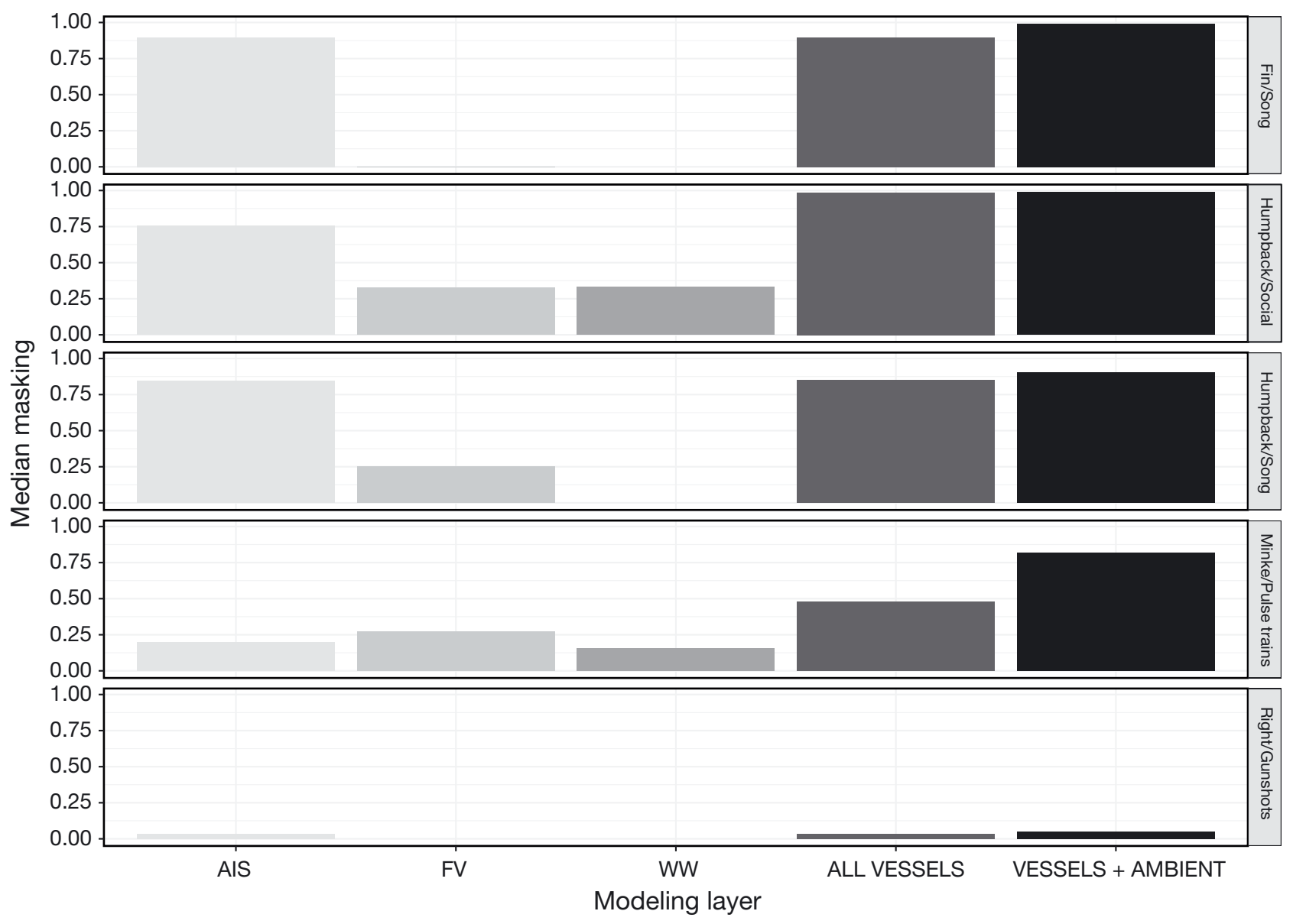

Fig. 5. Communication masking index for each sound type by vessel layer and for all layers combined. For each call type, the communication masking index was calculated for each animat every 10 min period over the $24 \mathrm{~h}$ analysis day. Results presented here are median values from all calculations and represent potential communication masking based on the grid of potential receivers used in the analyses. AIS: vessels with automatic identification system information; FV: fishing vessels; WW: whale-watching vessels; all vessels: masking from all vessel layers combined; vessels + ambient: total masking from all vessel layers and present ambient noise combined

(industry, passenger, research) varied by day, based on the number and types of vessels active in the study area. Industrial vessels consistently had a greater contribution to masking than the other AIS vessel categories, but our sample was too small for robust analyses at this level of detail.

Fishing and whale-watching vessels contributed substantially to masking for humpback whale social sounds, with over $30 \%$ loss of CS by either of those vessel layers alone. Cumulatively, these plus AIS vessels led to a $99 \%$ decrease in CS for humpback social sounds. Minke whale pulse trains, however, experienced greater masking from fishing vessels $(27 \%)$ than AIS vessels $(20 \%)$. Cumulatively, minke pulse trains experienced only $48 \%$ masking by all vessel layers combined based on the $24 \mathrm{~h}$ sample (Table 6, Fig. 5).
Total masking from ambient and vessel noise combined

The combination of current ambient noise conditions and present vessel noise led to a reduction in communication range of up to $82 \%$ as compared to reference conditions. Across species, this represented a loss of up to $21 \mathrm{~km}$, with a mean of $9.3 \mathrm{~km}$ (4.0 SD). The corresponding modeled communication area was reduced by $16 \mathrm{~km}^{2}$ for right whales to over $2100 \mathrm{~km}^{2}$ for fin whales (Fig. 4, Table 5). This resulted in a median communication masking index of $5 \%$ for right whale gunshots, while each of the other sound types were masked $82 \%$ or more (Table 6). For both fin whale song and minke whale pulse trains, masking by PrA conditions exceeded that from the vessel layers. Total masking for fin 


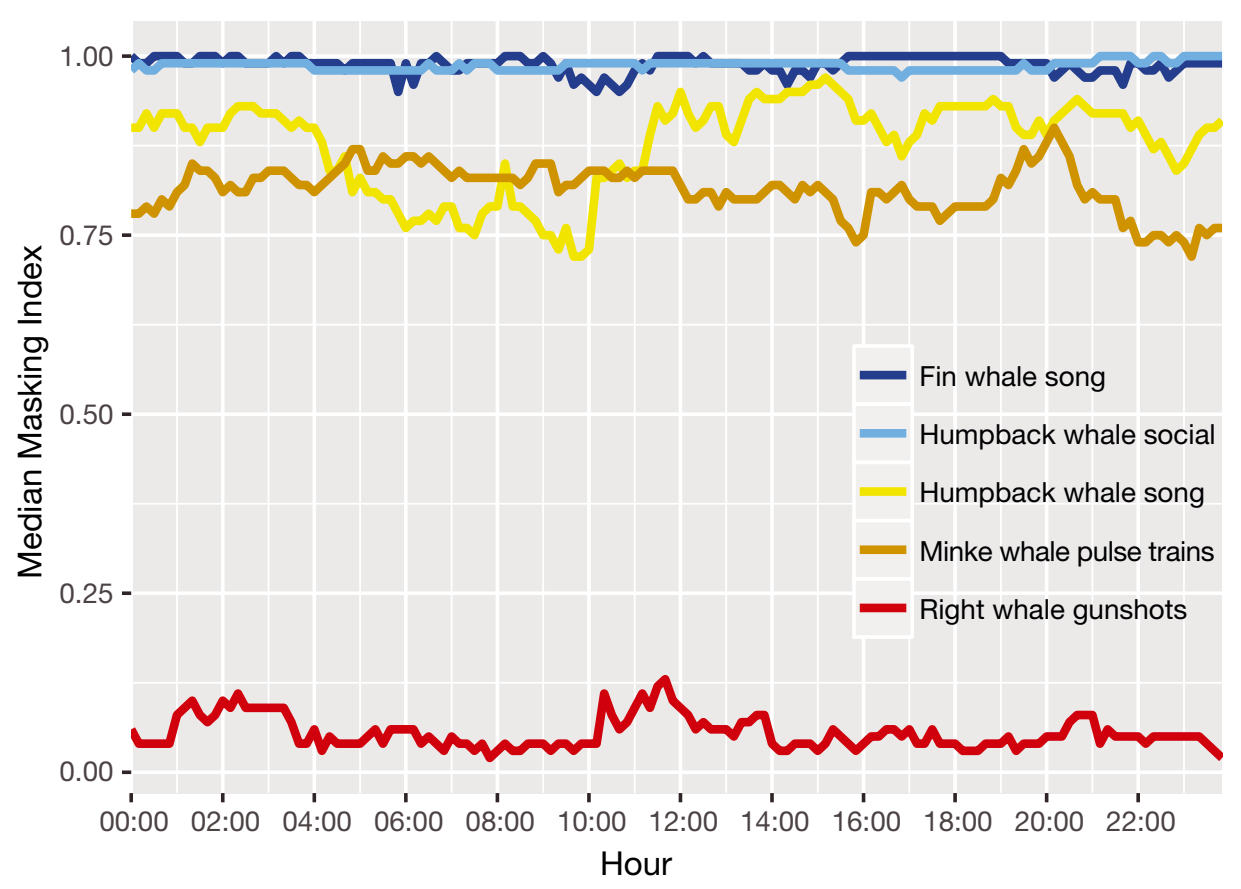

Fig. 6. Communication masking index, or proportion of communication space (CS) lost due to increased noise conditions, per species/sound type over one $24 \mathrm{~h}$ day. Masking was calculated as the ratio of the CS available under current noise conditions, including present ambient and discrete shipping noise, as compared to the CS available under reference ambient conditions. Note that a different day was analyzed for each species and sound type based on the seasonal occurrence of that species in the Stellwagen Bank National Marine Sanctuary. Median values at each $10 \mathrm{~min}$ time period are presented whales was estimated at $99 \%$ with the addition of ambient noise; masking for minke whales was increased to $82 \%$. Humpback whales suffered $90 \%$ or more loss in CS regardless of whether they were singing or producing social sounds.

In these single-day snapshots, median levels of masking were fairly consistent over the $24 \mathrm{~h}$ analysis period (Fig. 6). Humpback whales producing social sounds and singing fin whales experienced levels of potential communication masking that exceeded all other sound types.

\section{Additional analyses}

One of the strengths of an agent-based model is the ability to conduct an analysis multiple times, varying input parameters of interest. To assess the effect that initial animat placement had on the resulting measures of communication masking, modeling analyses were conducted 10 times for fin whales and humpback whales producing social sounds. In each model run, animats were randomly redistributed, while the other input parameters were held constant. Supplement 2 describes the detailed results from this additional modeling effort. Furthermore, a sensitivity analysis was also undertaken for both fin and humpback whales to consider the effect that the RD has on the estimates of communication masking. The RD was varied from 0 to $-12 \mathrm{~dB}$, in increments of $3 \mathrm{~dB}$, and the resulting communication range, area and masking index were calculated. Supplement 3 (at www.int-res.com/articles/suppl/n036p059_supp.pdf) contains details on these analyses and results.

\section{DISCUSSION}

The past decade has seen a rapid evolution in the methodologies and computational abilities used to address communication masking issues for a variety of species, in both terrestrial and marine environments. In the current study, we take the field one step further by implementing the framework developed in Clark et al. (2009) to include multiple species, call types and vessel types. By combining empirical data of vessel activity into an agent-based model of baleen whale movements, we are able to model received sound levels across a grid of potential receivers and quantify communication masking based on various combinations of ambient and vessel noise. This study represents a snapshot of the acoustic world of baleen whales in Massachusetts Bay, recognizing that the results include several simplifying assumptions and are meant to demonstrate a modeling approach and provide relative comparisons between species. Future work could expand on these analyses to evaluate fluctuations in CS experienced by the species in this region across seasons and years.

To quantify the effects of ambient noise on the area over which animals are able to communicate, comparison to a reference condition is necessary. Choos- 
ing an appropriate reference noise level is critical, as it directly influences estimation of communication masking under current ambient noise conditions. In a review of sources of noise in the ocean, Hildebrand (2009) suggested that low-frequency noise may have increased $20 \mathrm{~dB}$ or more compared to pre-industrial conditions, particularly in regions affected by commercial shipping. Hatch et al. (2012) took a conservative approach and used a reference of $-10 \mathrm{~dB}$ in their calculation of communication masking for North Atlantic right whales. Our study followed the latter approach, recognizing that this may underestimate loss of CS for some species. One of the insights emerging from our daily snapshots is that multiple species of baleen whales utilizing the waters of Massachusetts Bay and the SBNMS may suffer significant loss of CS for a variety of sound types. With the exception of right whale gunshots, present levels of ambient noise alone, which include a variety of distant anthropogenic activities, may contribute to a reduction in over $50 \%$ CS for all call types analyzed, including right whale up-calls as previously reported in Hatch et al. (2012). As the SBNMS and surrounding waters are key foraging habitats used annually by each of these species, the substantial loss of CS in such a biologically important area may have significant impacts on these species.

Massachusetts Bay and the SBNMS are heavily utilized by vessel traffic, and discrete vessel transits play a significant role in the acoustic environment of the region. One of the strengths of the approach utilized in this study is the ability to separate the contributions from different categories of vessels to the acoustic environment. In our daily snapshots, AIS vessels alone contribute to a reduction in CS of $75 \%$ or more for 3 of the call types analyzed. The Port of Boston is considered to be the largest in New England, and the majority of vessel traffic in the area is comprised of large cargo ships, including tankers, container ships and gas carriers (US Department of Commerce 2010). In $1 \mathrm{yr}$, over 3400 transits of large commercial vessels (AIS vessels) occurred through the SBNMS, and acoustic modeling has suggested that these vessels may ensonify an area the size of the entire sanctuary at levels of greater than $120 \mathrm{~dB}$ re $1 \mu \mathrm{Pa}$ when transiting through (Hatch et al. 2008). However, our analyses also demonstrate that smaller vessels, such as fishing and whale-watching vessels, may also have a consequential influence on the local acoustic habitat. For example, each of those vessel layers independently contributed to a decrease in over $30 \%$ of CS for humpback whales producing social vocalizations on a day during their summer foraging season. While AIS vessels show little change in behavior year-round, fishing and whale-watching vessel activity is more seasonally driven, with high levels of activity throughout the summer and fall. Stellwagen Bank has historically been one of the most important fishing grounds in the Gulf of Maine, and the sanctuary sees use from commercial fishing vessels from 6 states across New England, with an average of over 300 vessels per year (US Department of Commerce 2010). The whalewatching industry is also thriving, with more than 70000 tourists visiting the SBNMS on commercial whale-watching vessels in 2008 (O'Connor et al. 2009). One important caveat to consider is that the whale-watching boats in our model were not programmed to follow specific animats but instead were targeting the same subregion within which the animats were placed. Programming individual whalewatching boats to follow specific animats would require a number of assumptions for which we do not have the data, for example, the degree of avoidance exhibited by individual animals or the amount of time spent by individual boats within proximity to any particular group of whales. The approach taken in this study is a simplification of the whale-watching vessel operation and therefore may underestimate the acoustic impact from this type of vessel on individual animals. Additionally, other types of recreational vessels also utilize the waters surrounding the SBNMS throughout the year but were not included in the current study, as there is no methodology by which we could obtain vessel noise signatures or estimate their activity. Therefore, the true aggregate level of noise from vessel activity in this region may be higher than that modeled in our study.

Cumulatively, PrA noise levels combined with discrete vessel activity reduced CS over $80 \%$ for most species in the snapshots in our study. In a similar study conducted on the Pacific coast, Williams et al. (2014b) showed that across 12 important sites for fin whales, humpback whales and killer whales, CS was reduced in typical (median) conditions by 1, 52 and $62 \%$ and in noisy conditions by 30, 94 and $97 \%$, respectively, when compared to quiet conditions. The SBNMS is comparable to the noisy conditions measured for the Canadian Pacific, particularly for humpback whales. However, fin whales suffer a much greater loss of CS in our region, with $99 \%$ loss as compared to only $30 \%$ loss in Canada under the noisiest conditions. This difference is likely due in large part to propagation differences between the habitats. The SBNMS is a shallow-water environment, with minimum depths around $20 \mathrm{~m}$. Lowfrequency propagation, and therefore communica- 
tion range, in this environment is significantly inhibited even in the absence of other noise contributors. Given the poor propagation conditions for fin whales singing on Stellwagen Bank, the loss of CS estimated here may be exaggerated compared to other habitats.

The mechanics of estimating communication masking are now becoming well developed; however, there are assumptions and components of the models for which we still have high uncertainty. As discussed in a detailed review by Erbe et al. (2016), variables underlying signal DTs, such as the auditory response and critical ratios, are poorly understood for many species. Refinements in other variables such as the DI (in both the source and hearing capabilities of the receivers) can also be incorporated into the existing framework, once reasonable baseline estimates are developed for these values. Even estimates of historical communication ranges can be difficult without an appropriate understanding of the signal processing experienced by a receiver. One example where these uncertainties become problematic is in estimating the communication masking of signals such as right whale gunshots. These broadband impulsive signals are extremely loud, which increases their detectability at a distance. However, the spectral and temporal structures of these signals change significantly as they propagate, resulting in both frequency and time dispersion. One component of the framework developed by Clark et al. (2009) includes the RD, which accounts for an animal's ability to not only detect but also recognize a signal in background noise. The calculation of this RD includes SG, which incorporates the duration and signal bandwidth into the calculation of detectability. For signals such as right whale gunshots, estimating the appropriate SG for receivers at various distances is complex, and a static value may not be appropriate for both nearby and distant receivers that detect only a portion of the signal. Thus, while these gunshots may be detectable at our reference communication range, they may not be recognizable by conspecifics in the absence of other contextual information. Therefore, the actual CS experienced by animals producing this signal may be much less than that estimated using our parameters. Supplement 3 explores the effect of changing the RD for fin whales and humpback whales.

A variety of cetacean species exhibit some level of behavioral plasticity in response to noise, such as by increasing the amplitude, duration or frequency composition of their acoustic signals (e.g. Foote et al. 2004, Parks et al. 2007, Holt et al. 2009, Dunlop et al. 2014). Our calculations of CS loss do not take into account these types of compensatory mechanisms. However, the efficacy of these changes in maintaining successful acoustic communication between individuals and the long-term effects of these changes are also unknown.

Chronic noise exposure has many costs across species in addition to communication masking (Barber et al. 2010). Biologists are often asked to quantify the link between an environmental stressor, such as anthropogenic noise, and the long-term effects on the health of a population or species. Unfortunately, quantifying the links between noise impacts and individual reproductive success, and separating this from other environmental stressors, will likely be impossible to document in long-lived, slowly reproducing animals such as cetaceans. However, terrestrial studies on animals with higher fecundity can shed light on some potential direct fitness consequences. Studies are beginning to document a decline in reproductive success of individual avian species due specifically to noise (Habib et al. 2007), as well as declines in density and diversity of species across habitats (for a review, see Slabbekoorn \& Ripmeester 2008). Although these effects are documented in very different taxa, they may also be relevant for marine species, particularly considering that the effects of noise on individual stress levels have already been documented in baleen whales (Rolland et al. 2012). Increases in background noise levels will also affect an individual's ability to discern other important sounds in their environment. To the extent that an individual's ability to perceive acoustic cues affects predator avoidance, foraging success or navigation, loss of the ability to detect these signals may have additional consequences that are difficult to quantify. Future research efforts directed at improving our understanding of how baleen whales use acoustic signals for these vital life functions, and how much noise it takes to disrupt them, are crucial for more fully understanding the impacts of increased noise levels.

The species included in our study are exposed to increasing anthropogenic noise levels not only while in our study area but, for coastal migratory species such as right whales and humpback whales, across their migratory range along the eastern seaboard as well (Rice et al. 2014). The effects of noise and the loss of CS may have significant biological consequences, which is particularly worrisome for endangered species that rely on these habitats. This study provides further evidence for the need for national and regional strategies to address noise management in the marine environment. 
Acknowledgements. This work was supported by an Office of Naval Research grant (number N00014-07-1-1029) awarded by the National Oceanographic Partnership Program to C.W.C., L.T.H. and S.M.V.P. We thank Dave Wiley, Bob Wallace, Dave Arch, Stephen Kibner, Chris Fosdick and Brad Cabe for their assistance with field work and analyses of vessel data. We thank the staff at the Bioacoustics Research Program, particularly Chris Tessaglia-Hymes, Charlie Muirhead, Chris Pelkie, Mike Pitzrick and Peter Dugan, for their assistance with MARU deployments, data extraction and analysis preparation. We also thank Susan Parks and Cara Hotchkin for sharing right whale gunshot data. Finally, we thank Bill Ellison for discussions surrounding this project. The detailed comments of 4 anonymous reviewers significantly improved the manuscript.

\section{LITERATURE CITED}

Barber JR, Crooks KR, Fristrup KM (2010) The costs of chronic noise exposure for terrestrial organisms. Trends Ecol Evol 25:180-189

Bass AH, Clark CW (2003) The physical acoustics of underwater sound communication. In: Simmons AM, Fay RR, Popper AN (eds) Acoustic communication. Springer, New York, NY, p 15-64

Blackwell SB, Nations CS, McDonald TL, Greene CR, Thode AM, Guerra M, Macrander AM (2013) Effects of airgun sounds on bowhead whale calling rates in the Alaskan Beaufort Sea. Mar Mamm Sci 4:E342-E365

Bradbury JW, Vehrencamp SL (2011) Principles of animal communication, 2nd edn. Sinauer Associates, Sunderland, MA

Brenowitz E (1982) The active space of red-winged blackbird song. J Comp Physiol 147:511-522

Bruintjes R, Radford AN (2013) Context-dependent impacts of anthropogenic noise on individual and social behaviour in a cooperatively breeding fish. Anim Behav 85: 1343-1349

Calupca TA, Fristrup KM, Clark CW (2000) A compact digital recording system for autonomous bioacoustic monitoring. J Acoust Soc Am 108:2582

Chabot D (1988) A quantitative technique to compare and classify humpback whale (Megaptera novaeangliae) sounds. Ethology 77:89-102

Clark CW (1983) Acoustic communication and behavior of the southern right whale (Eubalaena australis). In: Payne $\mathrm{R}$ (ed) Communication and behavior of whales. Westview Press, Boulder, CO, p 163-198

Clark CW, Clark JM (1980) Sound playback experiments with southern right whales (Eubalaena australis). Science 207: 663-665

Clark CW, Borsani JF, Notarbartolo-di-Sciara G (2002) Vocal activity of fin whales, Balaenoptera physalus, in the Ligurian Sea. Mar Mamm Sci 18:286-295

* Clark CW, Ellison WT, Southall BL, Hatch L, Van Parijs SM, Frankel A, Ponirakis D (2009) Acoustic masking in marine ecosystems: intuitions, analysis, and implication. [See also Corrigendum in Mar Ecol Prog Ser 55:281]. Mar Ecol Prog Ser 395:201-222

* Croll DA, Clark CW, Acevedo A, Tershy B, Flores S, Gedamke J, Urban J (2002) Bioacoustics: only male fin whales sing loud songs. Nature 417:809

Dugan PJ, Ponirakis DW, Zollweg JA, Pitzrick MS and others (2011) SEDNA - bioacoustic analysis toolbox: Mat- lab platform to support high performance computing, noise analysis, event detection and event modeling. Conf Proc Oceans '11 MTS/IEEE Kona, 19-22 September 2011, Waikoloa, HI. http://ieeexplore.ieee.org/xpl/mostRecent Issue.jsp?punumber $=6093765$

* Dunlop RA, Noad MJ, Cato DH, Stokes D (2007) The social vocalization repertoire of east Australian migrating humpback whales (Megaptera novaeangliae). J Acoust Soc Am 122:2893-2905

* Dunlop RA, Cato DH, Noad MJ (2014) Evidence of a Lombard response in migrating humpback whales (Megaptera novaeangliae). J Acoust Soc Am 136:430

Fellison WT, Southall BL, Clark CW, Frankel AS (2012) A new context-based approach to assess marine mammal behavioral responses to anthropogenic sounds. Conserv Biol 26:21-28

* Ellison WT, Racca R, Clark CW, Streever B and others (2016) Modeling the aggregated exposure and responses of bowhead whales Balaena mysticetus to multiple sources of anthropogenic underwater sound. Endang Species Res 30:95-108

*EEbe C, MacGillivray A, Williams R (2012) Mapping cumulative noise from shipping to inform marine spatial planning. J Acoust Soc Am 132:EL423-EL428

* Erbe C, Reichmuth C, Cunningham K, Lucke K, Dooling R (2016) Communication masking in marine mammals: a review and research strategy. Mar Pollut Bull 103:15-38

Evans CS, Evans L (2007) Representational signalling in birds. Biol Lett 3:8-11

Eyring V, Köhler HW, Van Aardenne J, Lauer A (2005) Emissions from international shipping: 1. The last 50 years. J Geophys Res 110:D17

FFoote AD, Osborne RW, Hoelzel AR (2004) Whale-call response to masking boat noise. Nature 428:910

Frankel AS, Ellison WT, Buchanan J (2002) Application of the acoustic integration model (AIM) to predict and minimize environmental impacts. Oceans '02 MTS/IEEE 3: 1438-1443

*Habib L, Bayne EM, Boutin S (2007) Chronic industrial noise affects pairing success and age structure of ovenbirds Seiurus aurocapilla. J Appl Ecol 44:176-184

Hatch L, Clark C, Merrick R, Van Parijs S and others (2008) Characterizing the relative contributions of large vessels to total ocean noise fields: a case study using the Gerry E. Studds Stellwagen Bank National Marine Sanctuary. Environ Manage 42:735-752

*Hatch LT, Clark CW, Van Parijs SM, Frankel AS, Ponirakis DW (2012) Quantifying loss of acoustic communication space for right whales in and around a US National Marine Sanctuary. Conserv Biol 26:983-994

*Hatch LT, Wahle CM, Gedamke J, Harrison J and others (2016) Can you hear me here? Managing acoustic habitat in US waters. Endang Species Res 30:171-86

Hildebrand JA (2009) Anthropogenic and natural sources of ambient noise in the ocean. Mar Ecol Prog Ser 395:5-20

Holles S, Simpson SD, Radford AN, Berten L, Lecchini D (2013) Boat noise disrupts orientation behaviour in a coral reef fish. Mar Ecol Prog Ser 485:295-300

* Holt MM, Noren DP, Veirs V, Emmons CK, Veirs S (2009) Speaking up: killer whales (Orcinus orca) increase their call amplitude in response to vessel noise. J Acoust Soc Am 125:EL27-EL32

Khan C, Duley P, Henry A, Gatzke J, Cole T (2014) North Atlantic Right Whale Sighting Survey (NARWSS) and Right Whale Sighting Advisory System (RWSAS) 2013 
results summary. NEFSC Ref Doc 14-11. NMFS, Woods Hole, MA

King SL, Janik VM (2015) Come dine with me: food-associated social signalling in wild bottlenose dolphins (Tursiops truncatus). Anim Cogn 18:969-974

Klump GM (1996) Bird communication in the noisy world. In: Kroodsma DE, Miller EH (eds) Ecology and evolution of acoustic communication in birds. Cornell University Press, Ithaca, NY, p 321-338

Lohr B, Wright TF, Dooling RJ (2003) Detection and discrimination of natural calls in masking noise by birds: estimating the active space of a signal. Anim Behav 65:763-777

Matthews LP, McCordic JA, Parks SE (2014) Remote acoustic monitoring of North Atlantic right whales (Eubalaena glacialis) reveals seasonal and diel variations in acoustic behavior. PLOS ONE 9:e91367

McDonald MA, Hildebrand JA, Wiggins SM (2006) Increases in deep ocean ambient noise in the Northeast Pacific west of San Nicolas Island, California. J Acoust Soc Am 120:711-718

McKenna MF, Ross D, Wiggins SM, Hildebrand JA (2012) Underwater radiated noise from modern commercial ships. J Acoust Soc Am 131:92-103

McKenna MF, Wiggins SM, Hildebrand JA (2013) Relationship between container ship underwater noise levels and ship design, operational and oceanographic conditions. Sci Rep 3:1760

Mellinger DK, Carson CD, Clark CW (2000) Characteristics of minke whale (Balaenoptera acutorostrata) pulse trains recorded near Puerto Rico. Mar Mamm Sci 16:739-756

Moore SE, Randall RR, Southall BL, Ragen TJ, Suydam RS, Clark CW (2012) A new framework for assessing the effects of anthropogenic sound on marine mammals in a rapidly changing Arctic. Biomed Sci 62:289-295

* Morano JL, Rice AN, Tielens JT, Estabrook BJ, Murray A, Roberts BL, Clark CW (2012) Acoustically detected yearround presence of right whales in an urbanized migration corridor. Conserv Biol 26:698-707

Mussoline S, Risch D, Hatch LT, Weinrich MT and others (2012) Seasonal and diel variation in North Atlantic right whale up-calls: implications for management and conservation in the northwestern Atlantic Ocean. Endang Species Res 17:17-26

O'Connor S, Campbell R, Cortez H, Knowles T (2009) Whale watching worldwide: tourism numbers, expenditures and expanding economic benefits. Special report. International Fund for Animal Welfare, Yarmouth, MA

Parks SE, Clark CW (2007) Acoustic communication: social sounds and the potential impacts of noise. In: Kraus SD, Rolland RM (eds) The urban whale: North Atlantic right whales at the crossroads. Harvard University Press, Cambridge, MA, p 310-332

* Parks SE, Tyack PL (2005) Sound production by North Atlantic right whales (Eubalaena glacialis) in surface active groups. J Acoust Soc Am 117:3297-3306

Parks SE, Christopher CW, Tyack PL (2007) Short- and longterm changes in right whale calling behavior: the potential effects of noise on acoustic communication. J Acoust Soc Am 122:3725-3731

* Parks SE, Hotchkin CF, Cortopassi KA, Clark CW (2012) Characteristics of gunshot sound displays by North Atlantic right whales in the Bay of Fundy. J Acoust Soc Am 131:3173-3179

Payne RS, McVay S (1971) Songs of humpback whales. Science 173:585-597
Popper AN, Hawkins AD (eds) (2012) The effects of noise on aquatic life. Springer, New York, NY

Porter MB (2007) Acoustics toolbox. Underwater Acoustic Propagation Modeling Software. Science Applications International Corporation, 2002

Porter M, Liu YC (1994) Finite-element ray tracing. In: Lee D, Schulz $\mathrm{MH}$ (eds) Theoretical and Computational Acoustics, vol 2. World Scientific, Singapore, p 947-956

* Ratcliffe JM, Nydam ML (2008) Multimodal warning signals for a multiple predator world. Nature 455:96-99

* Rice A, Tielens JT, Estabrook BJ, Muirhead CA, Rahaman A, Guerra M, Clark CW (2014) Variation of ocean acoustic environments along the western North Atlantic coast: a case study in context of the right whale migration route. Ecol Inform 21:89-99

Richardson WJ, Greene CR Jr, Malme CI, Thomson DH (2013) Marine mammals and noise. Academic Press, San Diego, CA

* Risch D, Clark CW, Dugan PJ, Popescu M, Siebert U, Van Parijs SM (2013) Minke whale acoustic behavior and multi-year seasonal and diel vocalization patterns in Massachusetts Bay, USA. Mar Ecol Prog Ser 489:279-295

* Risch D, Siebert U, Van Parijs SM (2014) Individual calling behaviour and movements of North Atlantic minke whales (Balaenoptera acutorostrata). Behaviour 151:1335-1360

* Rolland RM, Parks SE, Hunt KE, Castellote M and others (2012) Evidence that ship noise increases stress in right whales. Proc R Soc B 279:2363-2368

Slabbekoorn H, Ripmeester EAP (2008) Birdsong and anthropogenic noise: implications and applications for conservation. Mol Ecol 17:72-83

* Slabbekoorn H, Bouton N, van Opzeeland IC, Coers A, ten Cate C, Popper AN (2010) A noisy spring: the impact of globally rising underwater sound levels on fish. Trends Ecol Evol 25:419-427

Stimpert AK (2010) Non-song sound production and its behavioral context in humpback whales (Megaptera novaeangliae). PhD dissertation, University of Hawai'i, Manoa, HI

US Department of Commerce (2010) Stellwagen Bank National Marine Sanctuary final management plan and environmental assessment. NOAA, Office of National Marine Sanctuaries, Silver Spring, MD

Voellmy IK, Purser J, Flynn D, Kennedy P, Simpson SD, Radford AN (2014) Acoustic noise reduces foraging success in two sympatric fish species via different mechanisms. Anim Behav 89:191-198

Vu ET, Risch D, Clark CW, Gaylord S and others (2012) Humpback whale song occurs extensively on feeding grounds in the western North Atlantic Ocean. Aquat Biol 14:175-183

*Wale MA, Simpson SD, Radford AN (2013) Noise negatively affects foraging and antipredator behaviour in shore crabs. Anim Behav 86:111-118

* Watkins WA, Tyack P, Moore KE, Bird JE (1987) The 20-Hz signals of finback whales (Balaenoptera physalus). J Acoust Soc Am 82:1901-1912

Williams R, Erbe C, Ashe E, Beerman A, Smith J (2014a) Severity of killer whale behavioral responses to ship noise: a dose-response study. Mar Pollut Bull 79:254-260

Williams R, Clark CW, Ponirakis DW, Ashe E (2014b) Acoustic quality of critical habitats for three threatened whale populations. Anim Conserv 17:174-185

Williams R, Erbe C, Ashe E, Clark CW (2015) Quiet(er) marine protected areas. Mar Pollut Bull 100:154-161

Submitted: July 1, 2015; Accepted: November 15, 2017

Proofs received from author(s): March 26, 2018
Editorial responsibility: Wendy Dow Piniak (Guest Editor), Gettysburg, Pennsylvania, USA 